\title{
Application of Software for the Prediction of Heat Loss in Outdoor Condition during Physical Activity in Nigeria
}

\author{
A. I. Musa ${ }^{a}$, S.O. Ismaila ${ }^{b}$, M.A. Waheed ${ }^{b}$ and T.M.A. Olayanju ${ }^{c}$ \\ ${ }^{a}$ Mechanical Engineering Department, Moshood Abiola Polytechnic, P.M.B. 2210, Abeokuta, Nigeria 110001 \\ ${ }^{b}$ Mechanical Engineering Department, Federal University of Agriculture, P.M.B. 2240, Abeokuta, Nigeria 110001 \\ ${ }^{c}$ Agricultural Engineering Department, Federal University of Agriculture, P.M.B. 2240, Abeokuta, Nigeria 110001
}

\begin{abstract}
The human body works to convert energy to provide desired thermal comfort level. This study developed a friendly-user software that is capable of determine and predict correctly the heat loss of a human being working in an outdoor environment. This task was with the use of mathematical model based on the conceptual heat balance equation of the human-environment interaction. There is lacks of computational simulation with user-friendly interfaces to simulating human body physiological responses in outdoor environment reference to the existing outdoor physical and physiological processes mathematical model. This study developed a simulation processes based on the mathematical model reported to determine the heat value, physical sweat rate production and predict the stored energy of human being working in an outdoor environment. This simulation presented was based on the $2^{\text {nd }}$ law of thermodynamics.
\end{abstract}

Keywords: Outdoor, Human, Software, Energy, Environment, Model, Heat balance.

\section{Introduction}

Thermal comfort is the condition of mind that expresses satisfaction with the thermal environment and is assessed by subjective evaluation [1-4], with no preference to warm or cooler conditions [2]. The concepts of outdoor thermal environment are complex and heterogeneous in nature. People working in an outdoor environment are exposed to a range of conditions. There six basic parameters that is of great importance to this study; these are air temperature $\left(\mathrm{T}_{\mathrm{a}}\right)$,radiant temperature $\left(\mathrm{T}_{\mathrm{r}}\right)$, relative humidity $(\mathrm{RH})$, wind speed $(\mathrm{v})$, human activity (metabolism), and clothing worn [5]. These parameters played a vital role in determine the condition of any human being working in an outdoor environment.

The main objectives of this study is to develop a friendly-user software that is capable of determine and predict correctly the heat loss of a human being working in an outdoor environment. The task was with the use of mathematical model based on the conceptual heat balance equation of the human-environment interaction. For human being to maintain heat balance with desired thermal environment, the internal temperature (core temperature) must be approximately $37^{\circ} \mathrm{C}$. Hence, the human body responds dynamically by keeping a constant core temperature in a dynamic environment.

Thermal comfort is maintained when the heat generated by human metabolism is allowed to dissipate, thus maintaining thermal equilibrium with the surroundings. The heat generated involves the body, heat transfer and heat storage [5]. The generated he in the body is as a result of metabolic activity (M), which offers the energy to perform the physical activity. The heat transfer is achieved through conduction $(\mathrm{K})$, convention $(\mathrm{C})$, radiation $(\mathrm{R})$, and evaporation (E) [5]. While the rate of heat storage is the rate of heat production and heat loss. If the body attains heat balance, the rate of heat storage would be zero [5].

Cheng and $\mathrm{Ng}$ [6] reported the broad application of concept and equipment used in biometeorology which has yielded a vast number of research on outdoor thermal comfort in

${ }^{*}$ Corresponding author. Tel.: +234)8035050573

E-mail: kunlemusa@yahoo.com

(c) 2015 International Association for Sharing Knowledge and Sustainability

DOI: $10.5383 /$ ijtee.09.01.006 
various seasons and climates around the world [7 - 13]. Many of these studies focus on modelling and assessment method from physiological perspectives [11],[12] while others conducted on the investigation of environmental parameters that determine the thermal comfort level of human being [9],[14].

The thermal environment is usually much cooler than people's skin in 'ordinary' situations and heat is lost through three methods: heat to transfer to the air (convention), evaporation of moisture and sweating, and radiation through the surrounding surfaces. The human thermal environments can be assessed by measuring environmental parameters, physiological responses as well as using thermal indices. The description of the environment would include values of air temperature, wind speed, humidity, and radiant temperature.

Metabolic heat production and clothing insulation are also required in any analysis of heat transfer between the body and the environment. The COMFA (COMfort FormulA) was applied to outdoor energy budget model to validate and simulate the modelling of thermal comfort on people performing physical activity [15 - 17]. For optimal thermal comfort, three basic conditions must be accomplished; the heat balance must exist, the skin temperature and the sweat rate must also be determined. However, there is lacks of computational simulation with users-friendly interfaces to simulating human body physiological responses in outdoor environment reference to the existing outdoor physical and physiological processes mathematical model by a smooth process flow.

This study is to develop a simulation processes based on the mathematical model reported to determine the heat values and physical sweat rate production and predict the stored energy of human being working in an outdoor environment. This simulation presented is based on the $2^{\text {nd }}$ law of thermodynamics.

\section{Human Heat Balance}

The heat generation involves the body, heat transfer and heat storage. The metabolic rate (M) offers energy to do the exercise (W) and the remainder is discharged as heat. Heat transfer is achieved by conduction (K), convection (C), radiation $(\mathrm{R})$ and evaporation $(\mathrm{E})$. The rate of heat storage $(\mathrm{S})$ is shown by the rate of heat production and heat loss. The heat balance equation for the human body can be represented with the body, heat transfer and heat storage $(\mathrm{M}$ and $\mathrm{W}$ are always positive and $\mathrm{E}, \mathrm{R}, \mathrm{C}$ and $\mathrm{K}$ are heat losses [5]. A negative heat loss is therefore a heat gain. $\mathrm{S}$ will be negative for heat loss and positive for heat gain.

The conceptual heat balance equation is

$$
\mathrm{M}-\mathrm{W}=\mathrm{E}+\mathrm{R}+\mathrm{C}+\mathrm{K}+\mathrm{S}
$$

$>$ If the body heat is balanced, the rate of heat storage would be zero.

$>$ If there were heat gain, storage would be positive and body temperature would rise.

However, if there were heat loss, storage would be negative and body temperature would decrease.

For heat balance $(S=0)$

$$
\mathrm{M}-\mathrm{W}-\mathrm{E}-\mathrm{R}-\mathrm{C}-\mathrm{K}=0
$$

In the 'ordinary' conditions, heat exchange by conduction is generally considered to be nominal and ignored. The practical heat balance equation is given by ASHRAE [5].

$$
\mathrm{M}-\mathrm{W}=\mathrm{Q}_{\mathrm{sk}}+\mathrm{Q}_{\mathrm{res}}=\left(\mathrm{C}+\mathrm{R}+\mathrm{E}_{\mathrm{sk}}\right)+\left(\mathrm{C}_{\mathrm{res}}+\mathrm{E}_{\mathrm{res}}\right)
$$

$\mathrm{M}=$ rate of metabolic energy production, $\mathrm{W} / \mathrm{m}^{2}$

$\mathrm{W}=$ rate of mechanical work, $\mathrm{W} / \mathrm{m}^{2}$

$\mathrm{Q}_{\mathrm{sk}}=$ total rate of heat loss from the skin, $\mathrm{W} / \mathrm{m}^{2}$

$\mathrm{Q}_{\text {res }}=$ total rate of heat loss through respiration, $\mathrm{W} / \mathrm{m}^{2}$

$\mathrm{C}=$ rate of convective heat loss from the skin, $\mathrm{W} / \mathrm{m}^{2}$

$\mathrm{R}=$ rate of radiative heat loss from the skin, $\mathrm{W} / \mathrm{m}^{2}$

$\mathrm{E}_{\mathrm{sk}}=$ rate of total evaporative heat loss from the skin, $\mathrm{W} / \mathrm{m}^{2}$

$\mathrm{C}_{\mathrm{res}}=$ rate of convective heat loss from respiration, $\mathrm{W} / \mathrm{m}^{2}$

$E_{\text {res }}=$ rate of evaporative heat loss from respiration, $\mathrm{W} / \mathrm{m}^{2}$

Therefore a practical approach is to consider heat production within the body $(M-W)$, heat loss at the skin $\left(C+R+E_{s k}\right)$ and heat loss due to respiration $\left(\mathrm{C}_{\mathrm{res}}+\mathrm{E}_{\mathrm{res}}\right)$.

\subsection{Required sweat rate production $\left(S_{w}\right)$}

Brotherhood [18] described the sweat production as independent parameter to the evaporative requirement and this is determined by the summation of heat arising from metabolism, radiation and convention which must be equal to the thermal balance. The response of sweat production is always determined by the core temperature [3] and affect by the skin temperature and temperature of the sweat gland [19]. The required sweat rate $\left(S_{\mathrm{W}}\right)$ is one of the rational indices for assessing heat stress. The $S_{w}$ index calculates the amount of sweat required for heat balance and supplies a practical method for interpretation of the $S_{w}$ through comparison of the amount of sweating required with the actual physiological capability of the human body. The $S_{w}$ index is developed from the six basic parameters such as air temperature $T_{a}$, radiant temperature $\mathrm{T}_{\mathrm{r}}$, relative humidity $\phi$, air velocity $v$, clothing insulation $\mathrm{I}_{\mathrm{cl}}$, metabolic rate $(\mathrm{M})$ and external work $(\mathrm{W})$. The evaporation required $\left(\mathrm{E}_{\mathrm{req}}\right)$ is calculated from

$$
\mathrm{E}_{\text {req }}=\mathrm{M}-\mathrm{W}-\mathrm{C}_{\text {res }}-\mathrm{E}_{\text {res }}-\mathrm{C}-\mathrm{R}
$$

The respiratory heat loss is often expressed in term of sensible $C_{\text {res }}$ and latent $E_{\text {res }}$. During the respiration, the body losses heat through convention and evaporation of heat through the skin and air and water vapour from the respiratory tract to the inhaled air.

The dry respiration heat loss per unit body surface area $\left(\mathrm{C}_{\mathrm{res}}\right)$ can hence be deduced as

$$
\mathrm{C}_{\text {res }}=0.0014 \mathrm{M}\left(\mathrm{T}_{\mathrm{sk}}-\mathrm{T}_{\mathrm{a}}\right)--
$$

The evaporative heat loss from respiration, $\mathrm{E}_{\mathrm{res}}$ is

$$
\mathrm{E}_{\text {res }}=0.0173 \mathrm{M}\left(\mathrm{P}_{\mathrm{sk}, \mathrm{s}}-\mathrm{P}_{\mathrm{a}}\right)-
$$

The total heat loss by respiration $=\mathrm{C}_{\mathrm{res}}+\mathrm{E}_{\mathrm{res}}$

The sensible heat loss from skin surface passes through clothing to the surrounding environment. Bothe convective $\mathrm{C}$ 
and radiative heat losses from the body can be express in term of heat transfer coefficient and the difference between the skin temperature and the environmental temperature.

$$
\mathrm{C}=\mathrm{h}_{\mathrm{c}} \mathrm{F}_{\mathrm{cl}}\left(\mathrm{T}_{\mathrm{sk}}-\mathrm{T}_{\mathrm{a}}\right)
$$

The thermal heat flow exchange by radiation, $\mathrm{R}$ can be calculated also as

$$
R=h_{r}\left(A_{r} / A_{D}\right) f_{c l}\left(T_{s k}-T_{r}\right)
$$

The total heat loss at skin $=\mathrm{C}+\mathrm{R}+\mathrm{E}_{\mathrm{sk}}$

The clothing area factor, $\mathrm{f}_{\mathrm{cl}}$

$$
\mathrm{f}_{\mathrm{cl}}=1+1.971 \mathrm{I}_{\mathrm{cl}}
$$

Clothing insulation,(clo) $\mathrm{I}_{\mathrm{cl}}=\mathrm{I}_{\text {top }}+\mathrm{I}_{\text {down }}+\mathrm{I}_{\text {boot }}$

The factor for heat exchange due to wearing cloth $\mathrm{F}_{\mathrm{cl}}$ can also be calculated as

$$
\mathrm{F}_{\mathrm{cl}}=1 /\left[1+\left(\mathrm{h}_{\mathrm{c}}+\mathrm{h}_{\mathrm{r}}\right) \mathrm{I}_{\mathrm{cl}}\right.
$$

The radiative heat transfer coefficient $\left(h_{r}\right)$ [5] is

$$
\mathrm{h}_{\mathrm{r}}=\sigma \varepsilon_{\mathrm{sk}}\left(\mathrm{A}_{\mathrm{r}} / \mathrm{A}_{\mathrm{D}}\right)\left[\left(\mathrm{T}_{\mathrm{sk}}+273\right)^{4}-\left(\mathrm{T}_{\mathrm{r}}+273\right)^{4}\right] /\left(\mathrm{T}_{\mathrm{sk}}-\mathrm{T}_{\mathrm{r}}\right)
$$

The surface radiating area $A_{r}$ of an average person is $1.8 \mathrm{~m}^{2}$ [1]

$$
\mathrm{A}_{\mathrm{D}}=0.202 \times \mathrm{W}_{\mathrm{b}}^{0.425} \mathrm{x} \mathrm{H}_{\mathrm{b}}^{0.725}
$$

The evaporative heat transfer coefficient $\left(h_{e}\right)$

$$
=\mathrm{LR} \times \mathrm{h}_{\mathrm{c}}
$$

The Lewis relation (LR) simply describes the relationship between convective heat transfer and mass transfer coefficients and equals, at typical indoor/outdoor conditions, $16.7 \mathrm{~K} / \mathrm{kPa}[20]$.

The convective heat transfer coefficient $\left(\mathrm{h}_{\mathrm{c}}\right)$ can be deduced

$$
\text { as } \mathrm{h}_{\mathrm{c}}=2.38\left(\mathrm{~T}_{\mathrm{sk}}-\mathrm{T}_{\mathrm{a}}\right)^{0.25}
$$

The factor of heat exchange by evaporation due to clothing factor, $\mathrm{F}_{\mathrm{p}, \mathrm{cl}}$ can also be calculated from:

$$
\mathrm{F}_{\mathrm{p}, \mathrm{cl}}=1 /\left(1+2.22 \mathrm{~h}_{\mathrm{c}} \mathrm{I}_{\mathrm{cl}}\right)
$$

The saturated vapour pressure at skin temperature, $\mathrm{P}_{\mathrm{sk}, \mathrm{s}}$ (at air temperature, $\mathrm{T}_{\mathrm{sk}}$ )

$$
\mathrm{P}_{\mathrm{sk}, \mathrm{s}}=0.1333 \exp \left[18.956-4030 /\left(\mathrm{T}_{\mathrm{sk}}+235\right)\right]
$$

The saturated vapour pressure at air temperature, $\mathrm{P}_{\mathrm{sa}}$ (at air temperature, $\mathrm{T}_{\mathrm{a}}$ )

$$
\mathrm{P}_{\mathrm{sa}}=0.1333 \exp \left[18.956-4030 /\left(\mathrm{T}_{\mathrm{a}}+235\right)\right]
$$

The partial vapour pressure in air, $\mathrm{P}_{\mathrm{a}}$

$$
\mathrm{P}_{\mathrm{a}}=\mathrm{RH} \% \times \mathrm{P}_{\mathrm{sa}}
$$

$$
\mathrm{E}_{\max }=\mathrm{h}_{\mathrm{e}} \mathrm{F}_{\mathrm{p}, \mathrm{cl}}\left(\mathrm{P}_{\mathrm{sk}}-\mathrm{P}_{\mathrm{a}}\right)
$$

The evaporative heat loss from skin $\mathrm{E}_{\mathrm{sk}}$ depends on the amount of moisture on the skin surface. If the Skin wettedness $\mathrm{w}$, is 1.0, then, $\mathrm{E}_{\mathrm{sk}}=\mathrm{E}_{\max }$ [5]. When the skin wettedness $\mathrm{w}$ is more than 1.0, then, this signifies that not all the sweating is evaporated in the body. Skin wettedness is strongly correlated with warm discomfort and is also a good measure of thermal heat stress.

Theoretically, skin wettedness can approach 1.0 while the body maintains thermoregulatory control [5].

Efficiency of Sweating, $r$, can be calculated as

$$
\begin{gathered}
r=1-\mathrm{w}^{2} / 2 \\
\mathrm{w}=\mathrm{E}_{\mathrm{req}} / \mathrm{E}_{\max }
\end{gathered}
$$

The skin wettedness $\mathrm{w}$, is the ratio of the actual evaporative heat loss to the maximum possible evaporative heat loss $\mathrm{E}_{\max }$ The maximum evaporation occurs when $\mathrm{w}=1$ [5].

From required evaporation $\left(\mathrm{E}_{\mathrm{req}}\right)$ and maximum evaporation $\left(E_{\max }\right)$ and sweating efficiency(r), the following formula can be calculated.

Reference to equations above, the required evaporation,

$$
\mathrm{E}_{\text {req }}=\mathrm{M}-\mathrm{W}-\mathrm{C}_{\mathrm{res}}-\mathrm{E}_{\text {res }}-\mathrm{C}-\mathrm{R}
$$

The $S_{w}$ is calculated by the following formulae [21].

$$
\mathrm{S}_{\mathrm{w}}=\mathrm{E}_{\mathrm{req}} / \mathrm{r}
$$

Hence, the heat storage, $\mathrm{S}$

S during the activity, $=\mathrm{E}_{\mathrm{req}}-\mathrm{E}_{\max }$

\section{Software Development}

On the basis of the above mathematical models provided in ASHRAE fundamental handbook 2001, simulation software was designed and developed. This is aiming at providing a practical simulation procedure which will be easy with friendly interfaces. The function of the simulation platform includes the main module: the pre-processing, solver and post processing. The pre-processing module focused on the human body, clothing, environment and other needed information for simulation.

The process of solving equations is followed by the post processing which focused on visualizing the data produced in the simulation. This simulation software was developed through Visual Basic 6 computer language which has evolved as a result of Graphical Users Interface (GUI) provided by the window operating system. The interface was divided into four segments. Each segment performed different activities successfully. This simulation needs the operator to define all the environmental conditions. Air temperature, wind speed, relative humidity, solar radiation and other parameters must be well defined. This is applicable to when the operator wishes to know how a mason, wearing specific clothes and 
doing specific work feel thermally if subjected to any type of condition to produce a useful available energy.

Exergy software was developed to predict the heat loss by the mason working in an outdoor environment and performing a physical activity such as blocklaying once the variables are supplied. But this software can be applicable to any activity provided the metabolic heat generation is acknowledged [5]. The software code used is presented as appendix. Figure 1 below displayed the main interface of the exergy software package developed for this purposes while figure 2 to figure 6 displayed the interfaces for the heat values and predicted chats.

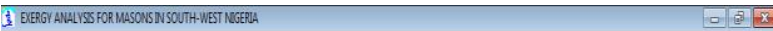
Setup Mantain Chats biegy Analyis

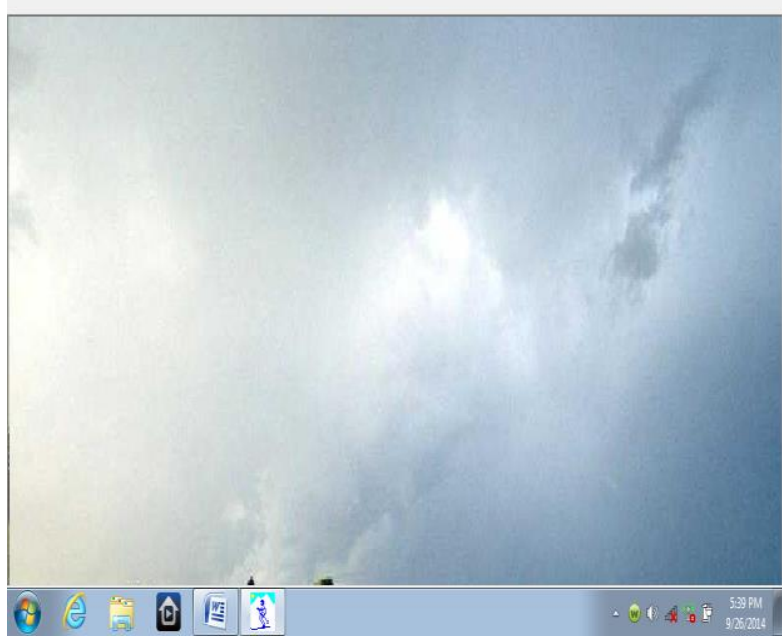

Figure 1: The main interface of Exergy Software

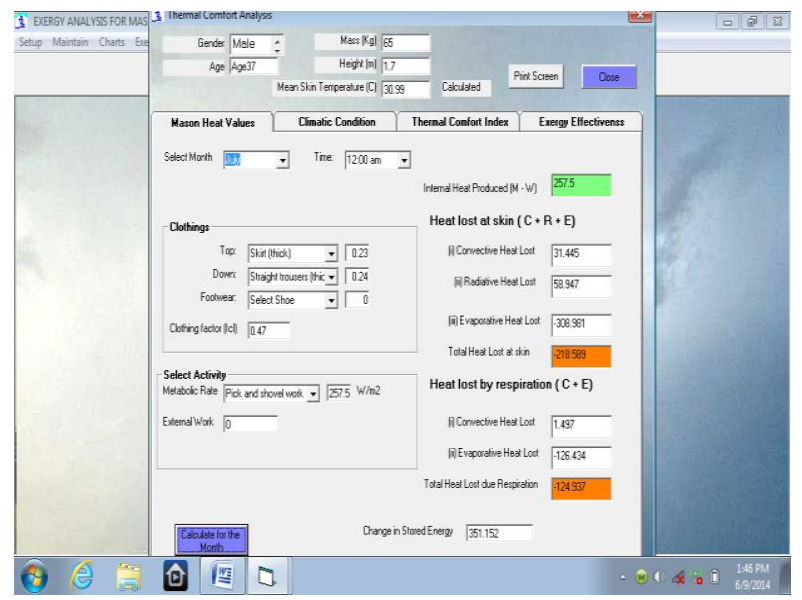

Figure 2: Interface for mason Heat values

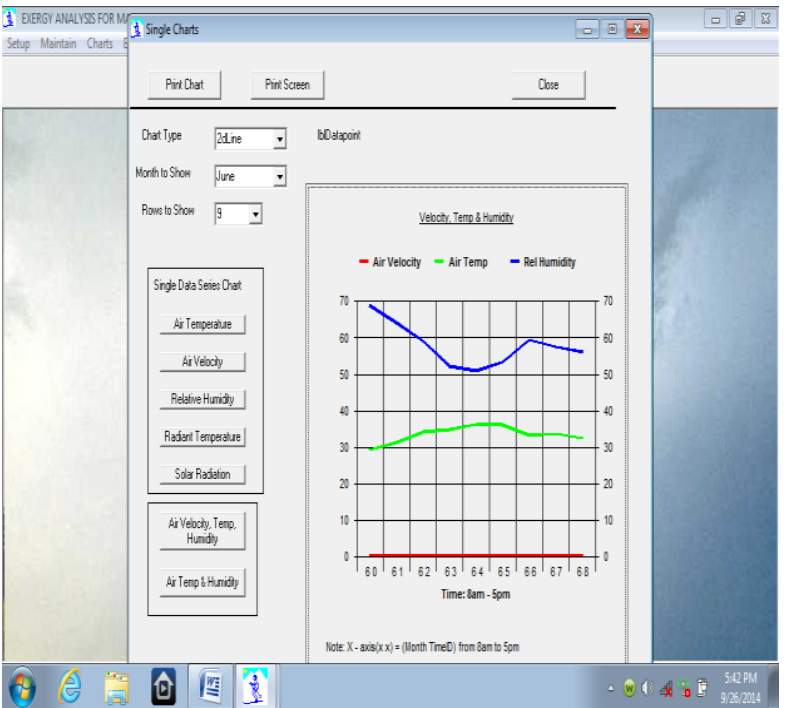

Figure 3: The predicted 2-dline chat

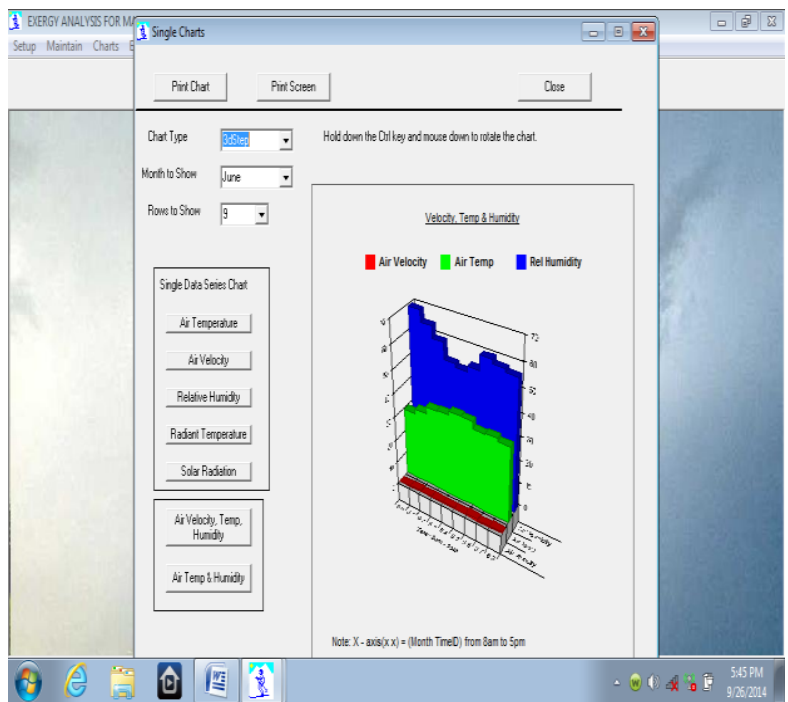

Figure 4: The predicted 3-dstep chat for June 2013

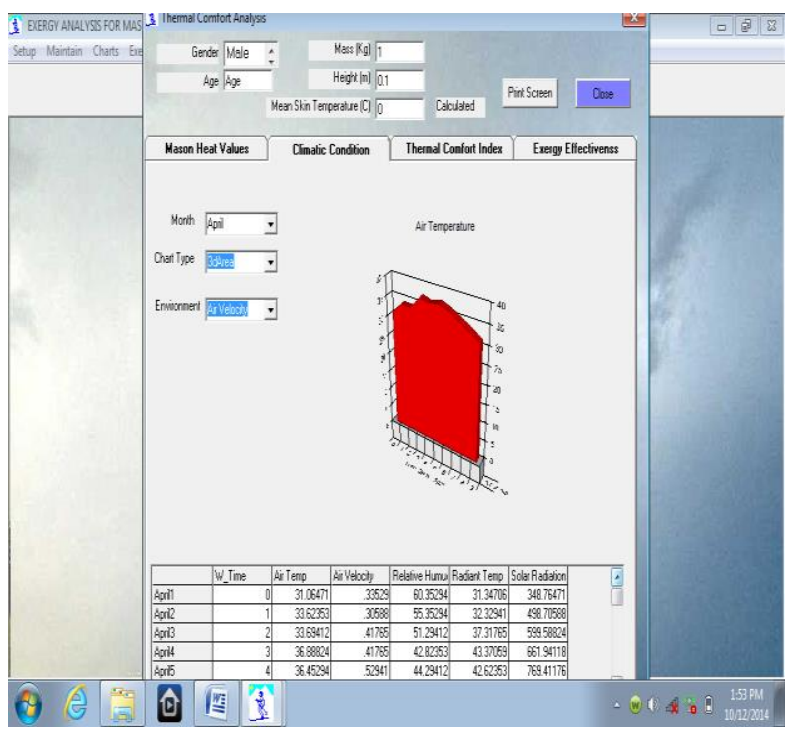

Figure 5: Interface for climatic condition for April 2014 


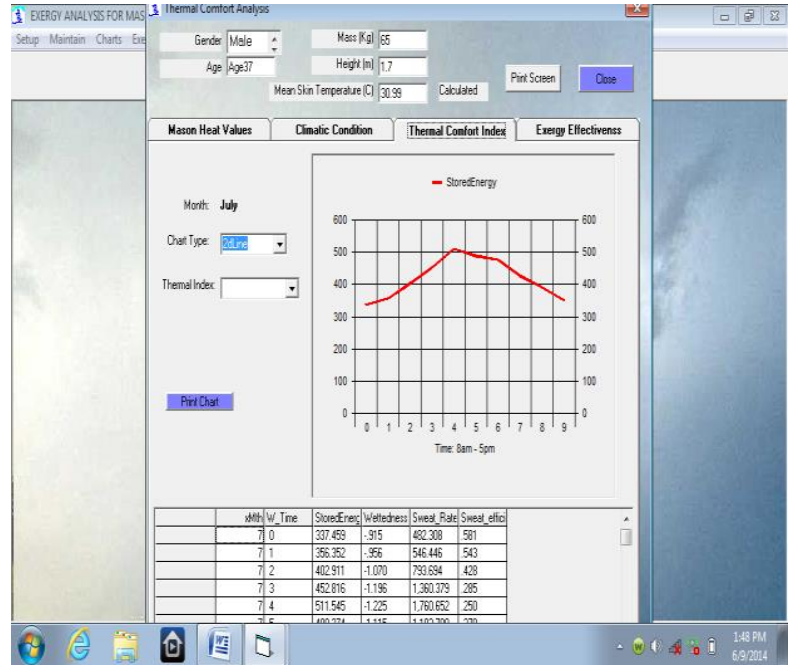

Figure 6: Interface for thermal index for July 2013

\section{CONCLUSION}

Thermal comfort and thermal sensation may be predicted in different ways. This developed software can be used to predict the heat loss of any human being with adjustment of clothing and activity level. More rigorous predictions are possible by using the Predicted Mean Vote (PMV) and Predicted Percentage of Dissatisfied (PPD) [5]. But this PMV and PPD are not in the scope of this study. The method presented here in the software is used to determine the stored energy, skin wettedness, sweat rate and its efficiency at every hour. This method is simple and it is based on the recorded variables either steady or unsteady state analysis.

Further research may include transient condition where the code will deal directly with the worker in harsh environmental condition gradually. That is, the worker will be connected to a computer by remote devices that will only send information about the conditions directly within the immediate vicinity. The computer code will then calculate the expected comfort indices and predict the heat loss of the worker and warn the workers ahead of time before getting to the critical limit of the comfort.

\section{References}

[1] ANSI/ASHRAE Standard 55 (2010), Thermal environmental conditions for human occupancy. ASHRAE, Atlanta, USA

[2] Fanger PO (1972) Thermal comfort. McGrawHill, New York

[3] Parsons KC (2003) Human thermal environments: the effects of hot, moderate and cold environments on human health, comfort and performance, 2nd edn. Taylor and Francis, New York.

[4] ISO7730 (2005): ergonomics of the thermal environment: analytical determination and interpretation of thermal comfort using calculation of the PMV and PPD indices and local thermal comfort criteria. ISO, Geneva.

[5] ASHRAE (2001). Physiological principles and thermal comfort. ASHRAE handbook of fundamentals (Chapter 8 ed., pp. 8.1-8.28). Atlanta, USA.

[6] Cheng Liang and $\mathrm{Ng}$ Edward, (2012), "Outdoor thermal comfort and outdoor activities: A review of research in the past decade" Cities (29); Pp 118 - 125.

[7] Ahmed KS (2003) Comfort in urban spaces: defining the boundaries of outdoor thermal comfort for the tropical urban environments. Energy Build 35(1):103-110.

[8] Ali-Toudert F, Mayer H (2007) Effects of asymmetry, galleries, overhanging facades and vegetation on thermal comfort in urban street canyons. Sol Energy 81(6):742-754.

[9] Cheng Liang and Ng Edward (2006), "Thermal comfort in urban open spaces for Hong Kong" Architectural Science Review, 49(3), $236-242$.

[10]Cheng, V., Ng, E., Chan, C., \& Givoni, B. (2010). "Outdoor thermal comfort study in sub-tropical climate: A longitudinal study based in Hong Kong". International Journal of Biometeorology. doi:10.1007/s00484-0100396-z.

[11] Hoppe P (2002). Different aspects of assessing indoor and outdoor thermal comfort. Energy and Buildings 34(6):661-665.

[12] Gulyas A, Unger J, Matzarakis A (2006) Assessment of the microclimatic and human comfort conditions in a complex urban environment: modelling and measurements. Build Environ 41(12):1713-1722.

[13] Nikolopoulou M and Lykoudis S (2006) "Thermal comfort in outdoor urban spaces: analysis across different European countries". Build Environ 41(11):1455-1470.

[14] Spagnolo J and de Dear RJ (2003) A field study of thermal comfort in outdoor and semioutdoor environments in subtropical Sydney Australia. Build Environ 38(5):721-738.

[15] Brown RD and Gillespie TJ (1986) Estimating outdoor thermal comfort using a cylindrical radiation thermometer and an energy budget model. Int J Biometeorol 30(1):43-52.

[16] Kenny NA, Warland JS, Brown RD and Gillespie TJ (2009a) Part A: assessing the performance of the COMFA outdoor thermal comfort model on subjects performing physical activity. Int J Biometeorol 53(3) 221231 
[17] Kenny NA, Warland JS, Brown RD and Gillespie TJ (2009b) Part B: Revisions to the COMFA outdoor thermal comfort model for application to subjects performing physical activity. Int J Biometeorol 53(4) 121-132.

[18] Brotherhood JR (2008) Heat stress and strain in exercise and sport. J Sci Med Sport 11(1):6- 19 .

[19] Shibasaki M, Wilson TE, Crandall CG (2006) Neural control and mechanisms of eccrine sweating during heat stress and exercise. $\mathrm{J}$ Appl Physiol 100(5):1692-1701.

[20] ASHRAE (2005), Thermal Comfort chapter, Fundamentals volume of the ASHRAE Handbook, ASHRAE, Inc., Atlanta, GA

[21]ISO7933. (1989). Hot environments -analytical determination and interpretation of thermal stress using calculation of required sweat rate. Geneva: International standards organization. 